University of Wollongong

Research Online

Faculty of Engineering and Information

Faculty of Engineering and Information

Sciences - Papers: Part A

Sciences

$1-1-2016$

\title{
Water reclamation and nitrogen extraction from municipal solid waste landfill leachate
}

Long D. Nghiem

University of Wollongong, longn@uow.edu.au

Faisal I. Hai

University of Wollongong, faisal@uow.edu.au

Andre Listowski

University of Wollongong, Sydney Olympic Park Authority, andrzej@uow.edu.au

Follow this and additional works at: https://ro.uow.edu.au/eispapers

Part of the Engineering Commons, and the Science and Technology Studies Commons

Research Online is the open access institutional repository for the University of Wollongong. For further information contact the UOW Library: research-pubs@uow.edu.au 


\title{
Water reclamation and nitrogen extraction from municipal solid waste landfill leachate
}

\begin{abstract}
This study aims to explore several innovative technologies including electrocoagulation, nanofiltration (NF), membrane distillation (MD), and ion exchange resin for clean water extraction and resource recovery from landfill leachate. Our results demonstrate the technical feasibility of water reuse and ammonia recovery from landfill leachate. Electrocoagulation was effective as a pretreatment step for the NF process and could remove most suspended solids and some organic matter. The results show that the combination of NF and MD can produce high-quality water from landfill leachate suitable for reuse applications with respect to heavy metals (with the exception of arsenic) and pharmaceutically active compounds (PhACs). Heavy metal concentrations in the NF permeate were below the values specified by the Australian Guidelines for Water Recycling. PhAC removals by the NF process were in the range of 67-97\%. Heavy metals and PhACs were not detectable in the MD distillate. The recovery of ammonia from NF permeate by a strong acid ion exchange resin was also demonstrated.
\end{abstract}

\section{Keywords}

water, waste, solid, municipal, landfill, extraction, leachate, nitrogen, reclamation

\section{Disciplines}

Engineering | Science and Technology Studies

\section{Publication Details}

Nghiem, L. D., Hai, F. I. \& Listowski, A. (2016). Water reclamation and nitrogen extraction from municipal solid waste landfill leachate. Desalination and Water Treatment, 57 (60), 29220-29227. 


\title{
Water reclamation and nitrogen extraction from municipal solid waste landfill leachate
}

\author{
Long D. Nghiem *a, Faisal I. Hai ${ }^{\text {a }}$, and Andrzej Listowski ${ }^{\text {a,b }}$
}

${ }^{a}$ Strategic Water Infrastructure Laboratory, School of Civil, Mining and Environmental Engineering, University of Wollongong, NSW 2522, Australia

${ }^{\mathrm{b}}$ Sydney Olympic Park Authority, Sydney Olympic Park, NSW 2127, Australia

*Corresponding author

\section{Contact details}

Long D. Nghiem - Email: longn@uow.edu.au; Tel: (+61) 242214590.

Faisal I. Hai - Email: Faisal@uow.edu.au; Tel: (+61) 242213054

Andrzej Listowski - Email: Andrzej.Listowski@ sopa.nsw.gov.au; Tel: (+61) 297147404

\begin{abstract}
This study aims to explore several innovative technologies including electrocoagulation, nanofiltration (NF), membrane distillation (MD) and ion exchange resin for clean water extraction and resource recovery from landfill leachate. Our results demonstrate the technical feasibility of water reuse and ammonia recovery from landfill leachate. Electrocoagulation was effective as a pretreatment step for the NF process and could remove most suspended solids and some organic matter. The results show that the combination of NF and MD can produce high quality water from landfill leachate suitable for reuse applications with respect to heavy metals (with the exception of arsenic) and pharmaceutically active compounds (PhACs). Heavy metal concentrations in the NF permeate were below the values specified by the Australian Guidelines for Water Recycling. $\mathrm{PhAC}$ removals by the NF process were in the range of 67 to $97 \%$. Heavy metals and PhACs were not detectable in the MD distillate. The recovery of ammonia from NF permeate by a strong acid ion exchange resin was also demonstrated.
\end{abstract}

Keywords: landfill leachate, ammonia recovery, water reuse, nanofiltration, electrocoagulation, membrane distillation, ion exchange resin. 


\section{Introduction}

Landfilling has been a predominant method of municipal solid waste management in many parts of the world [1]. The comparatively low upfront disposal cost is a major reason for the dependence on landfills for municipal solid waste management, particularly in the developing economies. Several highly developed countries including the USA, Australia, and Finland are also still heavily reliant on landfilling given their readily available landfill space [1].

Although the upfront waste disposal cost of landfilling is low, the associated long term landfill management costs, regulatory compliance requirements and environmental impacts are significant. The use of landfills is being phased out by more environmentally friendly methods, particular those that allow for simultaneous resource recovery and municipal solid waste management. Nevertheless, there remain thousands of active landfills with 10-30 years of operational lifetime $[1,2]$. There are also thousands of recently closed landfills that still require active emission management. In addition to the emission of landfill gas, the generation and release of landfill leachate also presents a serious threat to the environment [3].

Leachate is generated from precipitation onto the landfill surface, the moisture of the waste itself and, to some extent groundwater permeation (if the bottom of the landfill is not lined with geomembrane or clay) or other forms of water infiltration [3]. During the percolation through the body of the landfill, the infiltrated water is severely contaminated with a complex mixture of hazardous organic and inorganic contaminants. Any release of leachate containing large number of toxins into the groundwater or surface waters may present a significant risk to human health and the environment. As the volume of waste and a number of landfills increases, the likelihood of leachate escaping to environment is also surging. Thus reliable leachate collection and its subsequent treatment is important for the protection of surface and subsurface water bodies [1].

Recent intensive research has heightened an urgent need to investigate new technologies that can be effective for the treatment of landfill leachate [3]. More importantly, the presence of heavy metals, pharmaceutically active compounds (PhACs) and other complex organic chemicals in landfill leachate are of significant concern [4-6]. In particular, the contamination of various natural water bodies by landfill leachate poses further stress on the municipal water supply.

In addition to traditional biological treatment practices, more advanced methods such as coagulation-flocculation followed by a nanofiltration (NF) or reverse osmosis (RO) process has been extensively investigated for landfill leachate treatment [5, 7-10]. The limitations of such a combination include the high fouling rate of the membrane filtration process, difficulty in achieving a satisfactory ammonia removal rate, and the discharge of the concentrate (brine) generated in the NF/RO process. In a previous study, we have demonstrated that 
electrocoagulation is superior to conventional chemical coagulation in reducing organic and colloidal matter and thus protecting the NF membrane from fouling [9].

In this study, it is further demonstrated that coagulation followed by NF treatment can entail several other benefits. The NF membrane can effectively remove heavy metals and specific organic contaminants while allowing for a high passage of ammonia [11-13]. The innovative use of membrane distillation (MD) to further concentrate the NF brine to slurry will allow for the attainment of zero pollutants discharge. Several MD applications for treating highly saline waste solutions for water and mineral recovery have recently been demonstrated $[14,15]$, but not in conjunction with landfill leachate. In addition, the innovative use of strong acidic cation exchange resin will allow for complete removal of ammonia from the treated effluent. By regenerating the resin with nitric acid, ammonia can be effectively recovered in the form of $\mathrm{NH}_{4} \mathrm{NO}_{3}$, which is by itself a valuable product.

Thus, this study aims to explore several innovative technologies to address the above mentioned challenges. The feasibility of a hybrid process consisting of electrocoagulation, $\mathrm{NF}, \mathrm{MD}$ and ion exchange resin will be evaluated to achieve high quality treated effluent suitable for non-potable water reuse such as irrigation and environmental flow. Ammonia recovery by ion exchange resin is also demonstrated.

\section{Materials and Methods}

\subsection{Landfill leachate}

Landfill leachate was collected from an active municipal landfill in New South Wales, Australia. Sample was obtained from the collection lagoon prior to the ammonia removal plant. The collection lagoon was aerated for odour minimisation.

\subsection{Overall treatment train}

The proposed treatment train consisted of electrocoagulation pretreatment, NF, MD and ion exchange resin (Figure 1). Since ammonia is readily permeable through the NF membrane, the NF permeate is further treated by ion exchange resin for ammonia recovery. On the other hand, heavy metal and TrOC concentrations in the NF concentrate are order of magnitudes higher than those of the raw landfill leachate. Thus, MD is employed for an enhanced treatment capacity and to increase the overall water recovery. 

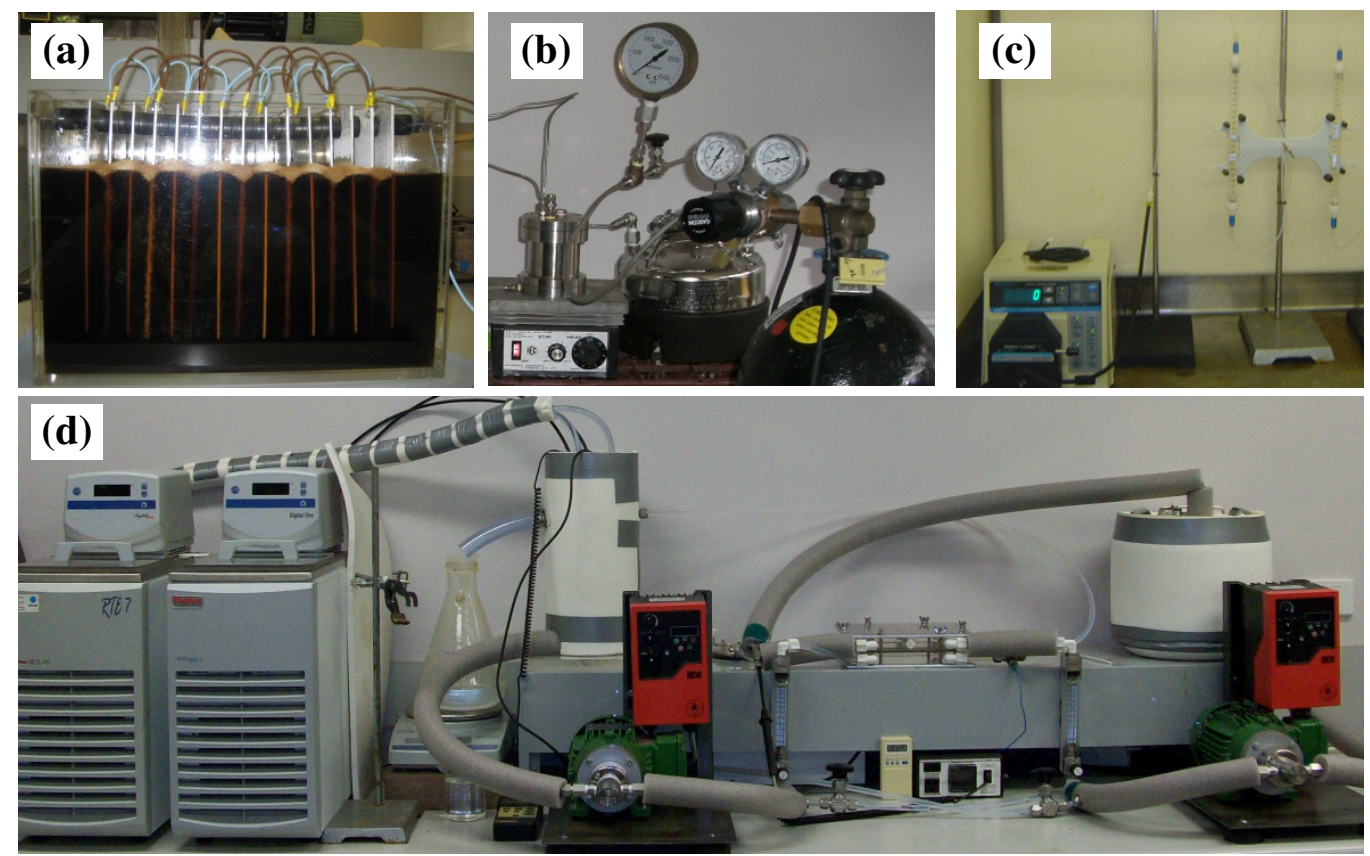

Figure 1: Experimental equipment in this study (a) electrocoagulation (b) NF filtration (c) ion exchange columns, and (d) DCMD system.

\subsection{Electrocoagulation}

In the electrocoagulation process, coagulant is produced by electrolysis. By applying a current, metallic ions from the anode plate are liberated into the aqueous solution. Hydrogen gas bubbles are formed and released from the cathode which causes the flotation process. The electrode reactions when using aluminum are:

Anode:

$$
A l_{(s)} \rightarrow A l^{3+}+3 e^{-}
$$

Cathode:

$$
2 \mathrm{H}_{2} \mathrm{O}+2 e^{-} \rightarrow \mathrm{H}_{2(g)}+2 \mathrm{OH}^{-}
$$

The $\mathrm{Al}^{3+}$ ions formed can efficiently remove organic matter, heavy metals, and even some ionic species such as fluoride through precipitation or co-adsorption to the precipitate. The precipitate is then captured by the $\mathrm{Al}(\mathrm{OH})_{3}$ flocs and floated into a gel state. The treatment equipment can be very compact and almost completely automated, and with the addition of sustainable technologies such as solar power, completely self-sufficient [16].

The electrocoagulation reactor is shown in Figure 1a. It consisted of an acrylic glass cell with a capacity of 8 liters, 15 aluminum electrodes $(25 \mathrm{~cm} \times 10 \mathrm{~cm} \times 0.3 \mathrm{~cm})$ in a monopolar configuration, and a DC power converter (Q1770, Dick Smith Electronics, Australia). Prior to each test, 6 liters of raw landfill leachate was introduced to the electrocoagulation cell. The current density and voltage were set at $25 \mathrm{~A} / \mathrm{m}^{2}$ and $2 \mathrm{~V}$, respectively. The flocs were allowed to settle for 2 hours and the supernatant was carefully extracted by piping out just below the surface of settled water. When not in use, the electrodes were immerged in an acid bath (1 M 
$\mathrm{HCl}$ ) and prior to each experiment, they were carefully cleaned using steel wool to remove any aluminum oxide on the surface.

\subsection{Nanofiltration}

NF experiments were conducted using a bench scale dead-end filtration system (Figure $1 \mathrm{~b}$ ) [9]. The stirred cell was made of stainless steel with an inner diameter of $56.6 \mathrm{~mm}$ resulting in a total membrane surface area of $21.2 \mathrm{~cm}^{2}$. This cell was connected to a 1 gallon (i.e. 3.79 L) stainless steel reservoir (Millipore). An Amicon magnetic stirrer was used and the stirrer speed was set at $400 \mathrm{rpm}$ to minimize concentration polarization effects on the membrane surface. Instrument grade air was used to pressurize the system. The permeate flux was measured by a digital balance which was connected to a personal computer.

The NF270 membrane was used. This is a loose NF membrane consisting of a semi-aromatic piperazine-based, polyamide layer on top of a microporous polysulfone support. A detailed characterization of this membrane is available elsewhere [17]. A new membrane was used for each experiment. Each experiment was conducted in two steps. The membrane was compacted for $1 \mathrm{~h}$ using MilliQ water at 10 bars. In the second step, the reservoir and cell were emptied and 1 liter of test solution was introduced to the reservoir. The pressure was set to 5 bars and six permeate samples of $100 \mathrm{~mL}$ each were collected for analysis.

\subsection{Ion exchange column}

A laboratory-scale ion exchange set-up was used in this study (Figure 1c). The set-up consisted of a Master Flex peristaltic pump, a feed reservoir, and two Omnifit ion exchange columns. These columns were made from a single boron silicate glass rod and were rated at $600 \mathrm{psi}$. The columns had a length of $250 \mathrm{~mm}$ and an internal diameter of $10 \mathrm{~mm}$. The columns were equipped with glass frit end caps.

Dowex Mono Upcore 600 ion exchange resin was used for ammonia recovery. This is a strong acid cation exchange resin. The ion exchange resins were soaked in MilliQ water for at least 24 hours prior to use and were kept at $4{ }^{\circ} \mathrm{C}$. At the conclusion of each experiment, the resin was completely regenerated using $\mathrm{HNO}_{3}$ and rinsed thoroughly with Milli-Q water.

\subsection{Direct contact membrane distillation}

MD experiments were conducted using a closed-loop bench-scale direct contact membrane distillation (DCMD) system (Figure 1d). The membrane cell was made of acrylic plastic to minimize heat loss to the surroundings. The membrane cell can hold a flat-sheet membrane under moderate pressure differential without any physical support. The flow channels were engraved in each of two acrylic blocks that make up the feed and permeate semi-cells. Each channel is $3 \mathrm{~mm}$ deep, $95 \mathrm{~mm}$ wide, and $145 \mathrm{~mm}$ long; and the total active membrane area for mass transfer is $138 \mathrm{~cm}^{2}$. Further details of this DCMD system are available elsewhere [18]. 
A hydrophobic, microporous membrane - namely Magna PTFE - from GE/Osmonics (Minnetonka, MN) was used. This is a composite membrane having a thin polytetrafluoroethylene (PTFE) active layer on top of a polypropylene (PP) support sublayer. According to the manufacturer, the pore size and porosity of the membrane are $0.22 \mu \mathrm{m}$ and $70 \%$, respectively. The membrane thickness is $175 \mu \mathrm{m}$, of which the active layer thickness is approximately $5 \mu \mathrm{m}$.

\subsection{Experimental approach}

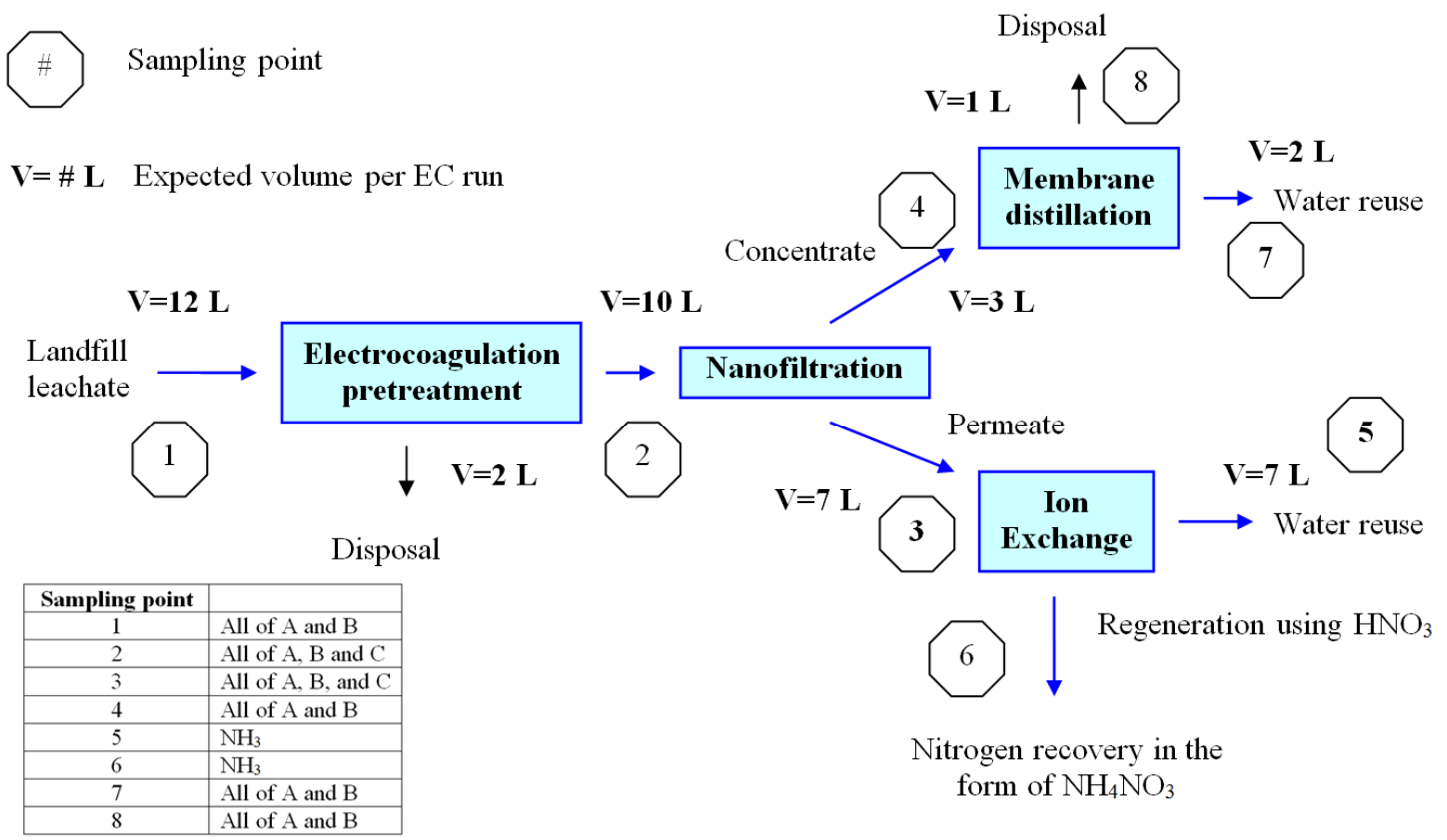

Figure 2: Experimental road map.

Table 1: Water parameters to be measured at each sampling point noted in Figure 2.

\begin{tabular}{|c|c|c|}
\hline A - Basic parameters & B - Heavy Metals & C - PhACs \\
\hline TOC & $\mathrm{Ag}$ & Sulfamethoxazole \\
\hline $\mathrm{TN}$ & As & Carbamazepine \\
\hline $\mathrm{NH}_{3}$ & $\mathrm{Cd}$ & Ibuprofen \\
\hline Colour & $\mathrm{Cu}$ & Triclosan \\
\hline $\mathrm{UV}_{254}$ & $\mathrm{Cr}$ & Diclofenac \\
\hline $\mathrm{pH}$ & $\mathrm{Pb}$ & \\
\hline Turbidity & $\mathrm{Ni}$ & \\
\hline TSS/TS & $\mathrm{Zn}$ & \\
\hline \multirow[t]{2}{*}{ Conductivity } & $\mathrm{Se}$ & \\
\hline & $\mathrm{Hg}$ & \\
\hline
\end{tabular}

The experimental road map of this study is outlined in Figure 2. Key water parameters and the corresponding sampling points are summarized in Table 1. Briefly, $12 \mathrm{~L}$ of raw landfill leachate was pretreated with electrocoagulation to obtain $10 \mathrm{~L}$ of supernatant. The supernatant was then treated by NF and the water recovery was set at $70 \%$. In other words, 
the NF process resulted in $7 \mathrm{~L}$ of permeate which was further treated with ion exchange resins for ammonia recovery. The NF concentrate was treated with MD with a water recovery of $67 \%$. Overall, the process resulted in $1 \mathrm{~L}$ of brine for every $10 \mathrm{~L}$ of supernatant from electroagulation pretreatment. Excluding the sludge from electrocoagulation pretreatment which can be returned to the landfill, the treatment train presented in Figure 2 can achieve $90 \%$ water recovery.

\subsection{Analytical techniques}

A Hach $2100 \mathrm{~N}$ turbidity meter was used for turbidity measurement. Conductivity and $\mathrm{pH}$ were measured using a Metrom 781 meter. Ammonia was also measured by a Metrom 781 Ion Meter equipped with an ammonia ion selective electrode (ISE). The Metrom 781 Ion Meter was calibrated daily. Total organic carbon (TOC) was measured using a Shimadzu TOC/TN analyser (model TOC- $\mathrm{V}_{\mathrm{VSH}}$ ).

Heavy metals and cation (e.g. $\mathrm{Na}^{+}, \mathrm{K}^{+}, \mathrm{Ca}^{2+}$, and $\mathrm{Mg}^{2+}$ ) concentration were determined using an Inductively Coupled Plasma - Mass Spectrometer (7500CS, Agilent Technologies, Wilmington, DE, USA) following the protocol previously reported by Tu et al. [19]. Anion concentrations were determined using an ion chromatography system (Shimadzu, Tokyo, Japan).

TrOC concentrations were determined using an analytical method previously reported by Hai et al. [20]. This method consisted of a solid phase extraction procedure followed by gas chromatography separation and quantitative determination using a mass spectrometry detector with electron ionization. Aqeuous samples (250 mL each) were extracted using $6 \mathrm{~mL}$ $200 \mathrm{mg}$ Oasis HLB cartridge (Waters, Milford, MA, USA). The extracted TrOCs were eluted from the cartridge using $7 \mathrm{~mL}$ of methanol followed by dichloromethane and methanol mixture $(1: 1 \mathrm{v} / \mathrm{v})$ at a flow rate of $1-5 \mathrm{~mL} / \mathrm{min}$. The eluents were subsequently evaporated using a water bath $\left(40{ }^{\circ} \mathrm{C}\right)$ under a gentle stream of nitrogen. The extracts were dissolved with $200 \mu \mathrm{L}$ methanol which contained $5 \mu \mathrm{g}$ bisphenol A-d $\mathrm{d}_{16}$ and transferred into $1.5 \mathrm{~mL}$ vials, and then further evaporated under a gentle stream of nitrogen. Finally, the extracts were derivatized by adding $100 \mu \mathrm{L}$ of $\quad$ N,O-Bis(trimethylsilyl)trifluoroacetamide (1\% trimethylchlorosilane) and pyridine (dried with $\mathrm{KOH}$ solid), then heated in a heating block $\left(60-70{ }^{\circ} \mathrm{C}\right)$ for $30 \mathrm{~min}$. The derivatives were cooled to room temperature and analysed using a Shimadzu QP5000 GC-MS (Shimadzu, Kyoto, Japan) equipped with a AOC20i autosampler and a Phenomenex Zebron ZB-5 (5\% diphenyl-95\% dimethylpolysiloxane) capillary column $\left(30 \mathrm{~m} \times 0.25 \mathrm{~mm} \mathrm{ID}, \mathrm{d}_{\mathrm{f}}=0.25 \mu \mathrm{m}\right)$. 


\section{Results and Discussion}

\subsection{Landfill leachate characterisation}

Key characteristics of the raw landfill leachate are summarised in Table 2. The raw landfill leachate was saline with an elevated concentration of sodium and chloride. The TOC concentration of this landfill leachate sample was order of magnitudes lower that that reported in our previous study [9]. Similarly, the ammonia content of this landfill leachate was about half of that commonly reported in the literature for young landfill leachate [21]. This is possibly due to the partial evaporation of ammonia from the aeration lagoon (section 2.1). On the other hand, the turbidity was high and was similar to our previous study. Of the ten heavy metals noted in Table 1, seven was detected in raw landfill leachate. The absence of silver, cadmium and mercury in this landfill leachate probably reflects the limited consumption of these heavy metals in consumer products and stringent environmental regulations in Australia. By contrast, all five PhACs were detected in raw landfill leachate at a notable concentration. The removal of heavy metals and PhACs will be discussed in the next section.

Table 2: Characteristics of raw landfill leachate (all units are in $\mathrm{mg} / \mathrm{L}$ except turbidity which is in NTU; average \pm standard deviation of three samples).

\begin{tabular}{|l|c|c|c|c|c|c|c|c|c|c|}
\hline Parameter & TOC & $\mathrm{pH}$ & Turbidity & $\mathrm{Na}^{+}$ & $\mathrm{K}^{+}$ & $\mathrm{Ca}^{2+}$ & $\mathrm{Mg}^{2+}$ & $\mathrm{NH}_{3}$ & $\mathrm{Cl}^{-}$ & $\mathrm{SO}_{4}{ }^{2-}$ \\
\hline Value & $37.6 \pm 1.1$ & 8.41 & $104 \pm 10$ & 1507 & 623 & 24 & 52 & 173 & 1167 & 55 \\
\hline
\end{tabular}

\subsection{Treatment performance}

Electrocoagulation pretreatment could remove most of the suspended solids prior to NF filtration. The removal efficiencies of turbidity and TOC by electrocoagulation were 75 and $60 \%$, which are consistent with values reported in our previous study [9]. Nevertheless, electrocoagulation was largely ineffective for the removal of dissolved contaminants including heavy metals, PhACs and colour. As can be seen in Table 3, the concentrations of some heavy metals (e.g. chromium, copper, selenium, and zinc) in the electrocoagulation supernatant were even slightly higher than those in raw landfill leachate. This observation could be attributed to the binding of heavy metals to suspended particles in raw landfill leachate. Some heavy metal bound suspended particles were removed by $0.45 \mu \mathrm{m}$ filter paper prior to ICP-MS analysis. The removal of PhACs by electrocoagulation was also negligible (data not shown).

The NF process effectively removed all heavy metals (with the exception of arsenic) to below the guideline values (Table 3). As expected, elevated concentrations of these heavy metals were found in the NF concentrate. However, given the excellent treatment capacity of MD for removing these contaminants, no heavy metals were detected in the MD distillate. 
As can be seen in Figure 3, the NF process was also effective for the removal of PhACs. The removals of PhACs by the NF270 were in the range of $67 \%$ (sulfamethoxazole) to $97 \%$ (triclosan). No PhACs investigated in this study were detected in the MD distillate.

Table 3: Concentration (in $\mu \mathrm{g} / \mathrm{L}$ ) of heavy metals at different sampling points of the proposed treatment process and the long term trigger value for non-potable water recycling.

\begin{tabular}{|l|c|c|c|c||c|c|c|}
\hline & $\begin{array}{c}\text { Raw } \\
\text { landfill } \\
\text { leachate }\end{array}$ & $\begin{array}{c}\text { EC } \\
\text { Supernatant }\end{array}$ & $\begin{array}{c}\text { NF } \\
\text { concentrate }\end{array}$ & $\begin{array}{c}\text { MD } \\
\text { concentrate }\end{array}$ & $\begin{array}{c}\text { NF } \\
\text { permeate }\end{array}$ & $\begin{array}{c}\text { MD } \\
\text { distillate }\end{array}$ & $\begin{array}{c}\text { Guideline } \\
\text { value }^{\mathbf{a}}\end{array}$ \\
\hline Silver & $<1$ & $<1$ & $<1$ & 2 & $<1$ & $<1$ & 100 \\
\hline Arsenic & 215 & 171 & 169 & 903 & 22 & $<1$ & 7 \\
\hline Cadmium & $<1$ & $<1$ & 2 & 3 & $<1$ & $<1$ & 2 \\
\hline Chromium & 185 & 202 & 436 & 2000 & 48 & $<1$ & 50 \\
\hline Copper & 12 & 87 & 156 & 808 & 8 & $<1$ & 2000 \\
\hline Nickel & 75 & 79 & 221 & 899 & 2 & $<1$ & 20 \\
\hline Lead & 2 & 3 & 5 & 29 & 1 & $<1$ & 10 \\
\hline Selenium & 45 & 52 & 41 & 171 & 35 & $<1$ & 100 \\
\hline Zinc & 124 & 145 & 410 & 937 & 14 & $<1$ & 3000 \\
\hline Mercury & $<1$ & $<1$ & $<1$ & 2 & $<1$ & $<1$ & 1 \\
\hline
\end{tabular}

${ }^{a}$ Guideline values are for secondary treated effluent intended for water reuse application from the Australian Guidelines for Water Recycling (Table 4.4).

-O-Rejection $\square$ Feed concentration $\square$ Permeate concentration

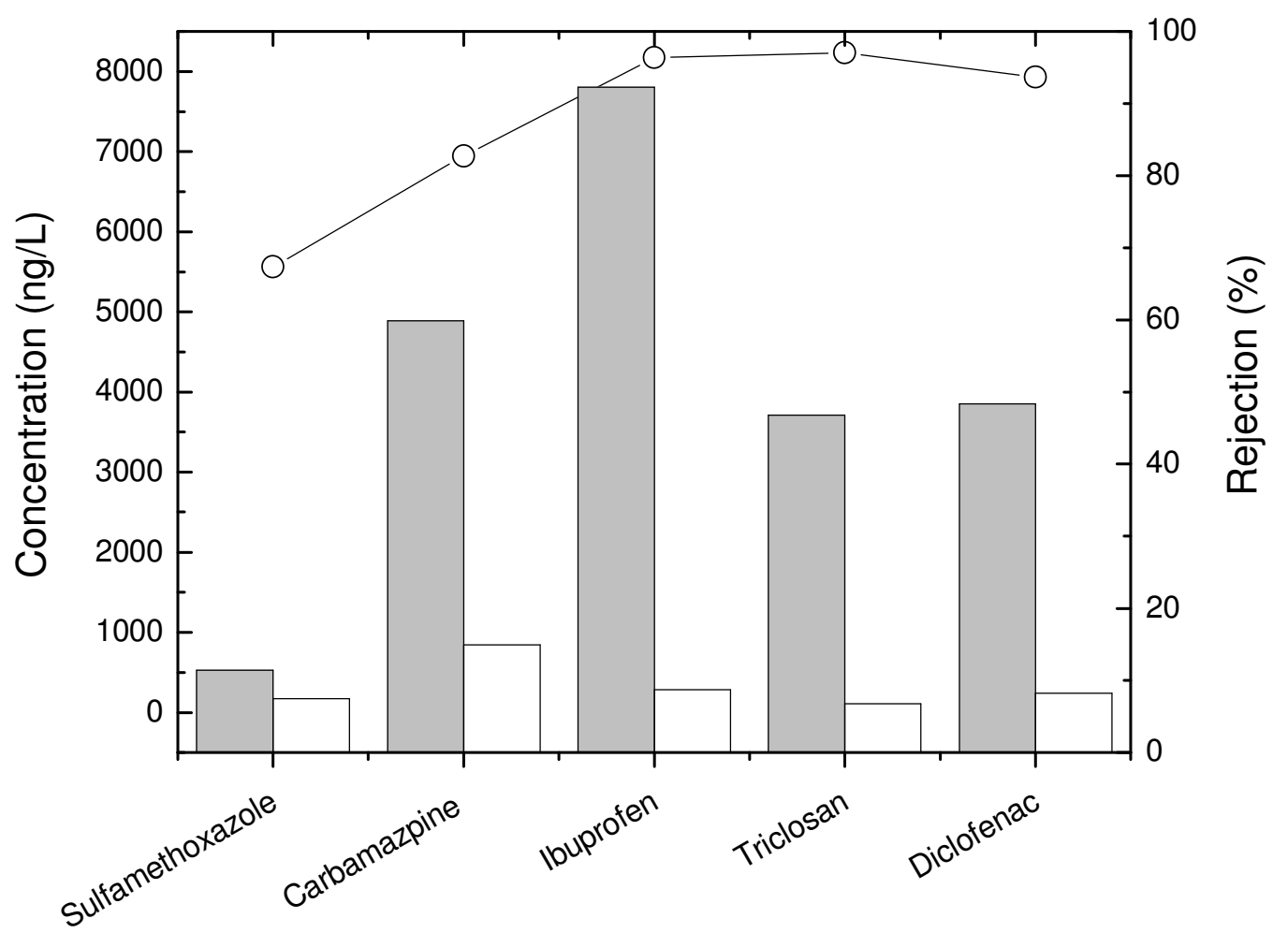

Figure 3: Removal efficiency of PhACs from landfill leachate by the NF270 membrane. Feed concentration $=$ sampling point number 2 and permeate concentration $=$ sampling point number 3 in Figure 2. No PhACs investigated in this study were detected in the MD distillate. 
Overall, with the exception of arsenic (NF permeate concentration of $22 \mu \mathrm{g} / \mathrm{L}$ compared to the guideline value of $7 \mu \mathrm{g} / \mathrm{L}$ ), results reported here demonstrate that the combination of NF and MD can produce high quality water from landfill leachate suitable for reuse application with respect to heavy metals.

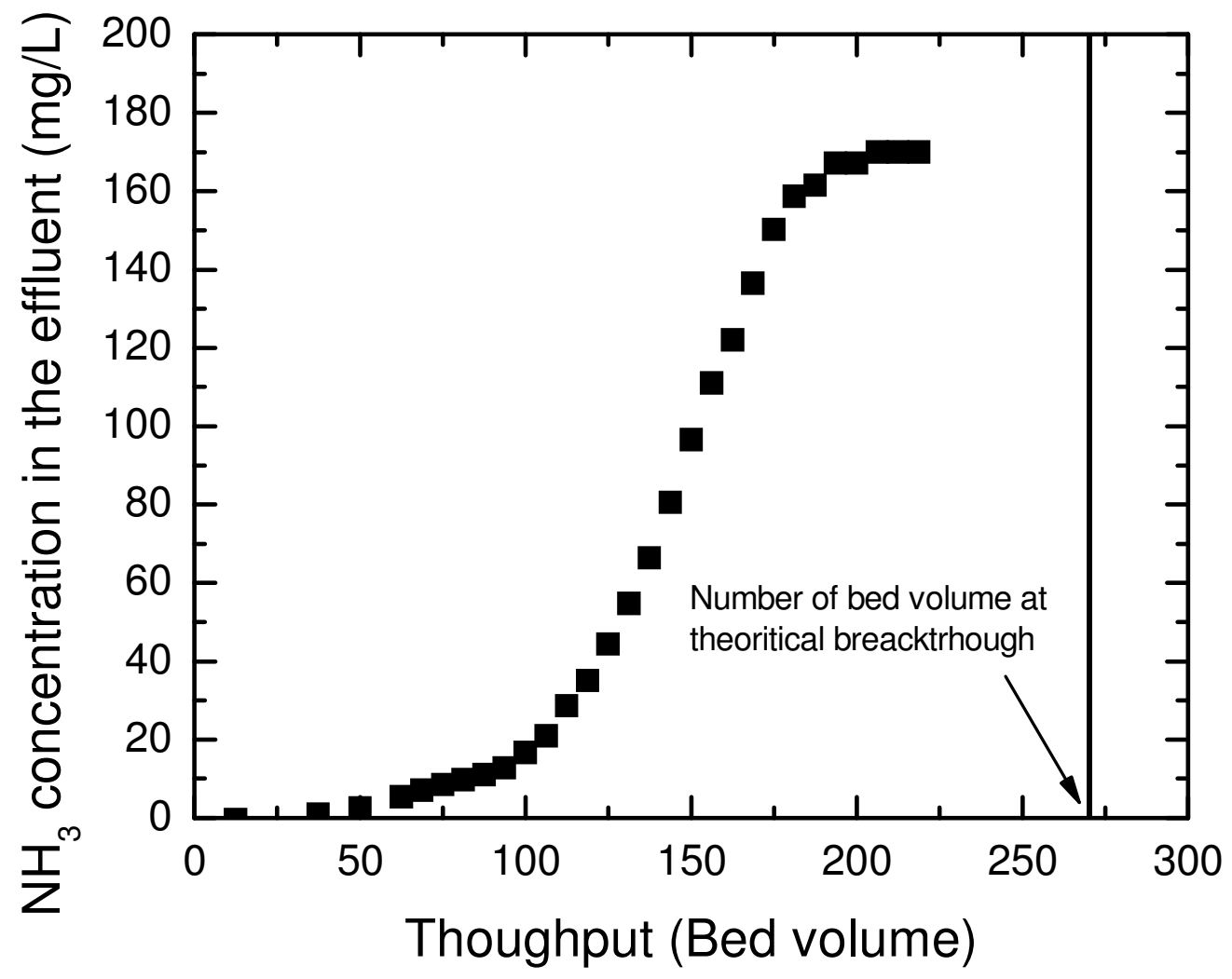

Figure 4: Break through profile of the ion exchange run using the Dowex Mono Upcore 600. The NF permeate was used as the influent. Bed volume $=160 \mathrm{~mL}$. The number of bed volume at the theoretical break through $(270 \mathrm{BV})$ was calculated based on the ion exchange capacity provided by the manufacturer.

No discernible ammonia removal by the NF membrane could be observed (data not shown). In other words, all ammonia was transferred from the raw landfill leachate to the NF permeate. A preliminary experiment was conducted to evaluate the performance of the Strong acid ion exchange resin (Mono Upcore C-600) for ammonia recovery from the NF permeate. As can be seen in Figure 4, a sharp breakthrough curve could be obtained. In other words, ammonia accumulation in the column was fast. The breakthrough value of approximately 100 bed volumes was achieved. This breakthrough volume is considerably less than the theoretical number of bed volumes of 270 calculated based on the manufacturer's specification (a total ion exchange capacity for this resin in $\mathrm{H}^{+}$form of $1.8 \mathrm{eq} / \mathrm{L}$ ). 
Nevertheless, the results demonstrate the potential to fully recover all ammonia from landfill leachate. It is also important to note that the experimental condition investigated here has not been optimised and that the ammonia concentration in raw landfill leachate was relatively low in this study. In addition, a detailed economic assessment is necessary to validate the practicality of this proposed treatment concept.

\section{Conclusion}

Results reported here demonstrate the technical feasibility of water reuse and ammonia recovery from landfill leachate. Electrocoagulation could be used as an alternative to traditional chemical coagulation. Although electrocoagulation does not efficiently remove dissolved solids, it could remove most suspended solids and some organic matter, thus, acting as an effective pretreatment step for the NF process. High concentration of ammonia in leachate is a serious environmental hazard. Although ammonia can readily be permeable through NF membrane, the NF process can remove most other cations, thus, allowing for effective ammonia recovery via ion exchange. Overall, with the exception of arsenic, the results show that the combination of NF and MD can produce high quality water from landfill leachate suitable for reuse applications with respect to heavy metals. Heavy metal concentrations in the NF permeate were below the guideline values specified by the Australian Guidelines for Water Recycling. Moderate to high PhAC removal by the NF process was also observed. Heavy metals and PhACs were not detectable in the MD distillate. The recovery of ammonia from NF permeate by a strong acid ion exchange resin was also demonstrated. Further study is recommended to optimise these treatment processes. Examples include various electrode materials, energy consumption and cell voltage efficiency of the electrocoagulation process and bed volume flowrate, temperature, and $\mathrm{pH}$ of the ion exchange process for ammonia recovery. In addition, it is also important to determine life cycle and demonstrate the cost effectiveness of the proposed hybrid system.

\section{Acknowledgement}

This research was supported under New South Wales Environmental Trust's Environmental Research Seeding Grants Program (project DOC09-43038). Laboratory assistance from Philipp Müller is gratefully acknowledged.

\section{References}

[1] Laner, D., M. Crest, H. Scharff, J.W.F. Morris, and M.A. Barlaz, A review of approaches for the long-term management of municipal solid waste landfills. Waste Manage., 2012. 32(3): p. 498-512.

[2] Jegatheesan, V., J.L. Liow, L. Shu, S.H. Kim, and C. Visvanathan, The need for global coordination in sustainable development. J. Clean. Prod., 2009. 17(7): p. 637643. 
[3] Visvanathan, C., M.K. Choudhary, M.T. Montalbo, and V. Jegatheesan, Landfill leachate treatment using thermophilic membrane bioreactor. Desalination, 2007. 204(1-3): p. 8-16.

[4] Huang, J.H., G. Ilgen, D. Vogel, B. Michalzik, S. Hantsch, L. Tennhardt, and B. Bilitewski, Emissions of inorganic and organic arsenic compounds via the leachate pathway from pretreated municipal waste materials: A landfill reactor study. Environ. Sci. Technol., 2009. 43(18): p. 7092-7097.

[5] Wintgens, T., M. Gallenkemper, and T. Melin, Occurrence and removal of endocrine disrupters in landfill leachate treatment plants, Water Sci. Technol. 2003. p. 127-134.

[6] Sanguanpak, S., C. Chiemchaisri, W. Chiemchaisri, and K. Yamamoto, Effect of organic fouling on micro-pollutant rejection in membrane bioreactor treating municipal solid waste landfill leachate. Water Sci. Technol., 2015. 72(4): p. 561-571.

[7] Košutić, K., D. Dolar, and T. Strmecky, Treatment of landfill leachate by membrane processes of nanofiltration and reverse osmosis. Desal. Wat. Treat., 2015. 55(10): p. 2680-2689.

[8] Top, S., E. Sekman, S. Hoşver, and M.S. Bilgili, Characterization and electrocaogulative treatment of nanofiltration concentrate of a full-scale landfill leachate treatment plant. Desalination, 2011. 268(1-3): p. 158-162.

[9] Mariam, T. and L.D. Nghiem, Landfill leachate treatment using hybrid coagulationnanofiltration processes. Desalination, 2010. 250(2): p. 677-681.

[10] Theepharaksapan, S., C. Chiemchaisri, W. Chiemchaisri, and K. Yamamoto, Removal of pollutants and reduction of bio-toxicity in a full scale chemical coagulation and reverse osmosis leachate treatment system. Bioresour. Technol., 2011. 102(9): p. 5381-5388.

[11] Verliefde, A., E. Cornelissen, G. Amy, B. Van der Bruggen, and H. van Dijk, Priority organic micropollutants in water sources in Flanders and the Netherlands and assessment of removal possibilities with nanofiltration. Environ. Pollut., 2007. 146(1): p. 281-289.

[12] Pellegrin, M.-L., A.D. Greiner, J. Diamond, J. Aguinaldo, L. Padhye, S. Arabi, K. Min, M.S. Burbano, R. McCandless, and R. Shoaf, Membrane Processes. Water Environ. Res., 2011. 83(10): p. 1187-1284.

[13] Fujioka, T., S.J. Khan, J.A. McDonald, and L.D. Nghiem, Rejection of trace organic chemicals by a nanofiltration membrane: the role of molecular properties and effects of caustic cleaning. Environ. Sci.: Water Res. Technol., 2015. 1: p. 846-854. 
[14] Duong, H.C., A.R. Chivas, B. Nelemans, M. Duke, S. Gray, T.Y. Cath, and L.D. Nghiem, Treatment of RO brine from CSG produced water by spiral-wound air gap membrane distillation - A pilot study. Desalination, 2015. 366: p. 121-129.

[15] Mericq, J.P., S. Laborie, and C. Cabassud, Vacuum membrane distillation for an integrated seawater desalination process. Desal. Wat. Treat., 2009. 9(1-3): p. 287-296.

[16] Chen, G., Electrochemical technologies in wastewater treatment. Sep. Purif. Technol., 2004. 38(1): p. 11.

[17] Nghiem, L.D., A.I. Schäfer, and M. Elimelech, Removal of Natural Hormones by Nanofiltration Membranes: Measurement, Modeling, and Mechanisms. Environ. Sci. Technol., 2004. 38: p. 1888-1896.

[18] Nghiem, L.D. and T. Cath, A scaling mitigation approach during direct contact membrane distillation. Sep. Purif. Technol., 2011. 80(2): p. 315-322.

[19] Tu, K.L., L.D. Nghiem, and A.R. Chivas, Coupling effects of feed solution pH and ionic strength on the rejection of boron by NF/RO membranes. Chem. Eng. J., 2011. 168(2): p. 700-706.

[20] Hai, F.I., K. Tessmer, L.N. Nguyen, J. Kang, W.E. Price, and L.D. Nghiem, Removal of micropollutants by membrane bioreactor under temperature variation. J. Membr. Sci., 2011. 383(1-2): p. 144-151.

[21] Alvarez-Vazquez, H., B. Jefferson, and S.J. Judd, Membrane bioreactors vs conventional biological treatment of landfill leachate: A brief review. J. Chem. Technol. Biotechnol., 2004. 79(10): p. 1043-1049. 